\title{
Above Word Equivalence and Strategies in the Indonesian Dubbed Series of We Bare Bears
}

\author{
A Anggraeni, R R Simanjuntak \\ English Department, Faculty of Humanities, Bina Nusantara University, Jakarta, Indonesia \\ *Corresponding author email: aanggraeni@binus.edu
}

\begin{abstract}
This study aimed to analyze the above word level translation strategies by Mona Baker that being applied, mostly used and its potential factors in $3 \mathrm{We}$ Bare Bears episodes. The data was analyzed using qualitative method. Analysis was done by comparing the English script and Bahasa dubbing. From the analysis, there were 5 strategies found. First translation using idiom with same meaning and form (14 times), translation using idiom with similar meaning but dissimilar form (32 times), translation by paraphrase ( 47 times), translation by omission ( 1 times) and error ( 6 times). Translation by paraphrase was the most used strategy in this research.
\end{abstract}

Keywords: Word Equivalence, Indonesian Dubbed Series, Bare Bears

\section{INTRODUCTION}

Language is a tool used by humans to communicate and convey messages and intentions to other figures. More than 6,500 languages in the world are used for everyday conversation, but due to differences in grammar and words, there is a method used as a helper for humans to communicate despite having different languages. In short, translation is a communication tool used to transfer meaning that has an equivalent (equivalent) from the source language to the target language $[1,2]$.

In general, there are several types of translation services available and according to their individual needs. Translation process is commonly understood to the legal translation, medical translation, as well as translation of the religious books or documents, as well as literacy translation. The purpose of the translation is clearly in the form of transferring meaning which has the same degree from the source language to the target language.

Despite having a clear intention, translating is not something that is easy to do, especially for translators. This can be caused by every language that has a style of language, structure and even culture that is different from one another. One thing that is often experienced by a translator is the difficulty of finding words or sentences that match and the same equivalent from the source language to the target language.

When translators are dealing with language elements such as words that have complicated meanings, speech, language structure and paragraph meanings, finding equivalence may be extra challenging. Therefore, a translator must find a way to avoid the fallacy or mismatch of meaning in the results of the translation. There are several ways which could be used to avoid problems with finding equivalence [2,3]. In specific, there were five effective principles in translation [3]. First, translation needs to be carried out in the word level. Second, translation needs to be carried out above the word. Third, translation needs to be carried out by looking at the language structure. Fourth, translation needs also be conducted by looking at the textual level. The last principle, or fifth, translation needs to be conducted also at the pragmatic level, or by looking carefully at the context of the language as the purpose for communication.

This present study aims at finding the translation strategies in the Indonesian dubbed version of the selected episodes for We Bare Bears cartoon series. We Bare Bears series are a program and cartoons that are aired on the channel owned by the United States namely Cartoon Network. We Bare Bears was first aired in 2015 and was made by Daniel Chong, an artist and animator from the United States. The research was conducted by answering these questions: (1) what problems in translation were identified in the dubbed version of the show, and (2) what strategies were implemented in dealing with these problems.

\section{PREVIOUS STUDIES}

Previous studies had been conducted in regards to this issue of problems in translation and the strategies in handling the problems. One of the strategies noted was in using the correct word and phrase [4]. It was found that there were 5 strategies implemented by translators in choosing the correct word. The strategy was by using more general words 
$(7.23 \%)$ in the translation, translation using the word loan $(17.67 \%)$, translation with cultural replacement $(7.23 \%)$, translation with omission $(33.33 \%)$ and translation using illustration $(7.63 \%)$. As for the translation strategy in the phrase level found as follows. Strategy with translation uses idioms that have the same meaning and form 17 times (35.42\%), translation uses idioms with the same meaning but different forms 16 times (33.33\%), translation by describing using words alone 15 times (31.25\%) [4].

Another study also identified the use of translation strategies in the phrase level [5]. Strategy with translation uses idioms that have the same meaning and form 2 times (2.85\%), translation uses idioms with the same meaning but different forms 3 times $(4.28 \%)$, translation by describing using words itself 62 times $(88.57 \%)$ and translation by removing 3 times $(4.28 \%)$ [5].

\section{RESEARCH METHODS}

The method used in this study was a qualitative research method, following the notion to use observation to collect data in form of paragraphs [6]. Through this research method, researchers are required to carry out the search for sources and literacy that are related or relevant to the topic to be studied. Researchers will also look for sources in the form of electronic books and electronic journals to become supporting material. The research method was chosen by the researcher to find out what translation strategies were used by the translator when translating the We Bare Bears source transcript into a form of translation over voice in Indonesian. It also includes what types of translation strategies are most widely used and their potential causes. Then how many degrees of inequality were found in the translation dubbing of We Bare Bears episodes.

For this study, the 3 episodes chosen by the researchers were random and each was taken from 3 seasons of We Bare Bears airing. The first episode is Yard Sale which is in season 2 episode 1. Then Primal is in season 1 episode 8 and Lucy's brother who is in season 3 episode 12 .

There are two stages undertaken by researchers when conducting this research, namely data collection and the process of analysing data. For the data collection stage, the researcher will first determine what topics will be analysed in general and in this study will analyze the scope of the study of translation. Both researchers chose the media to be used for analysis and the translator chose the media in the form of the translation of Indonesian dubbing from English in the selected 3 episodes of
We Bare Bears. Next is the selection of reference theory as the centre of this research. Researchers choose to use theories about translation strategies in the context of degree inequality in phrase levels according to Mona Baker. To get the data, the researchers continued to watch the three episodes and noted what components of the phase of the phrase would be analysed. Followed by researchers doing scanning and studying data that has been obtained from the media. With this, the data is complete and ready to be analysed.

Next is the data analysis process. First the researcher will look at the data collected from the data collection process. After that researchers will begin to analyse using existing theories, namely the translation strategy [3]. Each data will be analysed and finally it will be divided into 5 (five) categories according to existing theories. The translation of the translation strategy used idioms with meaning and form of the same, using the idiom translation with the same meaning but a different form, a translation by breaking with his own words, translation by disappearances and others. If all the data has been grouped into several existing strategies, the next step that needs to be taken by researchers is to draw conclusions from the data and make an analysis.

\section{RESULTS AND DISCUSSION}

In this chapter, researchers will provide an analysis of the data and discussion. After collecting data using the method described in chapter 3, 5 types of strategies were found in translating phrase levels in the $3 \mathrm{~B}$ episodes of We Bare Bears dubbing from the source language in this case English to the target language, Indonesian. The five types of strategies will be described as follows.

\subsection{Translation uses idioms with the same meaning and form}

This translation strategy used the technique of choosing idioms with similar meanings in the target language. Not only that, the chosen idiom also has a similar lexical type. Using this strategy is something that can sometimes be applied because actually every language has a different form and system. After analysing the data, here are some examples of using translation strategies using idioms with the same meaning and form.

Example 1. (Episode Lucy's brother) Source Language : Panda: Bye, Lucy! Your little bud is in a good hands 


\section{Target language : Panda: selamat tinggal Lucy. adikmu di tangan yang tepat}

The conversation occurred when Panda offered his help to take care of Lucy's younger brother. Lucy who was worried about the state of Clifford (her younger sister) finally agreed to let Clifford be guarded by Panda. Aiming to convince Lucy, Panda told Lucy that her sister was in the right hands or in her native language using the idiom "in a good hands".

The idiom "in a good hands" means the care of a person who is able to take care of someone or something well and the translator turns the Indonesian into the right hands [7]. Here it can be seen that the translator uses a translation strategy using idioms with the same meaning and form to translate these idioms.

Example 2. (Episode Yard Sale)
Source Language : Panda: Uh, I've
got to go. Don't bother me!
Target language
pergi, jangan hiraukan aku

The conversation took place when Panda suddenly got a text message on a cellphone he found while visiting Bazzar. Panda who panicked that the message for him felt he had to immediately reply. At that time, Panda immediately ran to his room and told Ice Bear that he must go or in the source language using the idiom "(have) got to go".

The idiom (have) got to go has the meaning required to leave in rush where what means someone must go in a hurry or quickly [7]. In this case, the translator translates to I have to go which has a similar meaning and lexical form with a meaning equivalent to the source language.

\subsection{Translation using idiom with similar meaning but dissimilar form}

The strategy is used when the translator can find idioms in the target language with the same meaning but have different lexical forms with the language. After analyzing the data, here are some examples of using a translation strategy using idioms with the same meaning but different forms.

$$
\begin{aligned}
& \text { Example 3. (Lucy's brother episode) } \\
& \text { Source language } \quad \text { : Lucy: Oh my gosh } \\
& \text { Target language }
\end{aligned}
$$

The above expression occurs when Lucy, who was driving her vehicle, felt suddenly panicked when she remembered her sister who was left with Panda.

The phrase Oh my gosh is often used when someone feels shocked, shocked, sad even in fear [8]. The translator translates the phrase Oh my gosh into gosh which has the meaning of a phrase similar to the source language, which is shocked or surprised. Translators use translation strategies using idioms that have the same meaning in different forms. Where the phrase Oh my gosh consists of 3 lexical items and oh my god consists of only 1 lexical item.

$$
\begin{aligned}
& \text { Example 4. (Primal episode) } \\
& \text { Source language : Grizzly: Whoa } \\
& \text { man, you don't look so hot! } \\
& \text { Target language } \quad \text { Grizzly: } \\
& \text { teman, } \text { kau kelihatan tidak terlalu baik }
\end{aligned}
$$

The above expression occurs when Grizz finds his brother in a bad condition. Grizz who had just returned from looking for food for his starving relatives saw that Panda and Ice Bear did not look so good that in the source language it didn't look so hot.

The idiom not look so hot has the meaning of feel slightly ill which means feeling sick and not too good. In this case, the translator uses a translation strategy using idioms with idioms with the same meaning but different forms [9]. Where the lexical of so hot translates to good.

\subsection{Translation by paraphrasing}

This strategy was done by describing using one's own words or paraphrase is the strategy most often used when the translator cannot find an appropriate idiom in the target language [3]. It can also be used when translators find it inappropriate to use idioms in the target language due to differences in style preferences. After analyzing the data, here are some examples of using a translation strategy by describing using your own words or paraphrases.

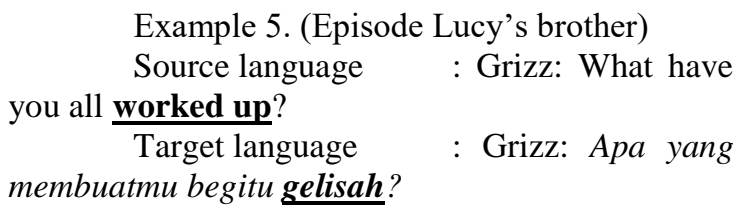

The conversation above occurred when Grizz was surprised by Panda's behavior that seemed nervous about something. The panda that looks uncharacteristically attracts Grizz by asking what 
makes Panda look so agitated or in the source language is worked up.

The phrase work up is a verb phrase that means to make yourself feel upset, excited and nervous [10]. The translator translates the phrase work up into anxiety which has the same meaning as it really is in the source language. So, it is known that the translator uses the strategy by describing using his own words or paraphrases while still having the same.

\section{Example 6. (Yard Sale) \\ Source language : Grizz: Let's see that little bundle of joy \\ Target language : Grizz: Mari kita \\ lihat bayinya}

The conversation above occurred when the three bears (Grizz, Ice Bear and Panda) finally entered the delivery room after Annie (the woman who was helped by the three bears when they wanted to give birth). Annie who had just given birth was seen carrying the baby and Grizz intended to see her baby in conversation using the idiom little bundle of joy.

The idiom bundle of joy has the meaning of a baby [11]. So it is known that the translator uses the strategy by describing using his own words but has the same. By changing the bundle of joy into one word that has the same meaning as the real meaning.

\subsection{Translation with omission}

The strategy used when one word or even one idiom intends to be removed entirely from one text was categorized as omission. Some of the reasons why it was deleted could be because the translator did not find words or idioms with the same, not suitable for paraphrase or could be for reasons of language style.

Example 7. (Primal Episode)

Source language:

Grizzly: C'mon you slow pokes

Target language:

Grizzly: Ayolah kalian

The conversation above occurred when Grizz invited his two brothers to go on a picnic into the forest. Ice Bear and Panda who walk behind Grizz look a little far from Grizz. Seeing his brother left behind, Grizz said slow pokes in the source language.

Slow pokes means someone who runs for a long and slow tempo [9]]. But if you look at the results of the translation, you can't find the meaning of the translated slow pokes but only refer to your words. So, it can be concluded that the translator uses the omission strategy in this case and automatically the meaning of slow pokes is not channeled into the results of the translation.

\subsection{Error translation}

From the data there some problems found in translating the episodes. Some cases of this phrase found meaning different from the real meaning.

Example 8. (Primal Episode)
$\begin{gathered}\text { Source language } \\ \text { living off the land, }\end{gathered}$
$\begin{gathered}\text { Target language } \\ \text { tinggal di luar keramaian }\end{gathered}$

The conversation occurred when Grizz invited Panda and Ice Bear to become ranger. Grizz who really wants to be a ranger invites Panda and Ice Bear to live off the land.

The phrase living off the land has the meaning of living and living by hunting animals and gardening themselves [9]. But in the target language, the phrase living off the land translates to living outside the crowd. So that found different meanings in the two phrases. So it is not known which strategy the translator uses in translating this phrase.

The phrase living off the land in the source language might be thought to have the same meaning as living outside the crowd where the word living has something in common with living. The word living is added to the preposition off it has a different meaning than just living outside the crowd [3]

Example 9. (Yard Sale)

Source language : Grizz: Stop. Back

up

dulu, $\underline{\text { kembali }}$

Target language : Grizz: Tunggu

In the example, the conversation above occurred when Grizz asked his two brothers to return when Grizz saw Bazzar. In the source language, Grizz said it with the phrase back up. The phrase back up has the meaning of moving backwards a short distance. But in the translation results, the translator uses the word back instead of the word back. It seemed that the problem was caused because the translator did not observe the context of the story carefully. In this case the problem was in translting the context of the message [3]. Rather than "kembali", the more appropriate expresion would be "mundur", indicating the motion of returning back to the position as if the bears were driving a car. 
After analyzing each of the lexical forms of the phrases as above, we can find out which strategies are most used in this study. To clarify which strategies are most widely used, researchers summarize them in the following table.

TABLE 1. Translation strategies

\begin{tabular}{|l|l|}
\hline Strategies dealing with above word level & Total \\
\hline $\begin{array}{l}\text { Translation using the same idiom with similar } \\
\text { meaning and form }\end{array}$ & 13 \\
\hline $\begin{array}{l}\text { Translation using the same idiom with similar } \\
\text { meaning but dissimilar form }\end{array}$ & 33 \\
\hline Translation by paraphrasing & 47 \\
\hline Translation by omission & 1 \\
\hline Error translation & 6 \\
\hline TOTAL & 100 \\
\hline
\end{tabular}

As seen from Table 1, the most used strategy is translation by paraphrasing. The findings of this result turned out to be in line with literatures [2,3], in which this strategy was the most frequently used strategy in translation.

In total there were 5 translation strategies used in translating the episodes. First is a translation using the same meaning and form was found 13 times, translation similar meaning and dissimilar form was found 33 times, translation by paraphrasing was found 47 times, translation with omission was found 1 times and 6 cases considered as error translation because the meaning from both language are different.

Translation errors found in the data was also caused by the lack of understanding for the medium of translation, which was video. This finding is in line with the literature, in which one of the important things that need to be considered in translating dubbing is to adjust the translation results with the speech movements of the original actors or voices $[1,2,3]$. This certainly makes the translator asked to find words in the target language that match the length or duration in the source language. As a result, there would be no discrepancy between speech rhythm and translation results in the target language related to the beauty of the translation results.

\section{CONCLUSION AND IMPLICATION}

From the data analysis, this research which is conducted by the researcher above shows that all 4 strategies that being mentioned by literatures. This research results were in line with the literature. Also, it was also seen that paraphrasing is the most common strategy to use when translator dealing with non-equivalence at above word level. As being seen from the analysis above, the translator of the $\mathrm{We}$ Bare Bears animated dubbing can be said to do a good translation result using phrases that are appropriate and have the same meaning as the source language. Although researchers found several phrases that do not have the same meaning as what is available in the dictionary.

Aware of the shortcomings that exist in this study, researchers suggest that researchers who are interested in conducting research in the scope of translation studies use research at a different level of strategy. In addition, it can also focus on the discovery of problems found. The researcher hopes that this study can be an appropriate reference source for researching translation strategies. Not only for researchers, it is hoped that this study can make viewers of We Bear Bears animated cartoons know what the strategy of translating dubbing from the source language, which is English to the target language, Indonesian.

\section{REFERENCES}

[1] Nida, E. A., Taber, C. R. 1974. The theory and practice of translation, Vol. 8, Netherland: Brill.

[2] Bhatia, N. 2019. The Oxford Companion to the English Language. Cambridge Dictionary. Cambridge University Press. Retrieved from: https://dictionary.cambridge.org/

[3] Baker, M. 1992. In other words: A coursebook on translation. London: Routledge.

[4] Suryoalam, A.T. 2011. A Study of Translation Strategies Used in Comic Translation of Lucky Luke: The Bridge on the Mississippi to Lucky Luke: Jembatan Mississippi. Skripsi S1. Universitas Dian Nuswantoro, Semarang.. 
[5] Ariyanto, K.B. 2013. Strategies used in translating idiomatic expression in the subtitle translation of the Transporter 2 movie. Skripsi S1. Universitas Dian Nuswantoro, Semarang.

[6] Babbie, E. 2014. The Basics of Social Research (6th Ed.). Belmont, California: Wadsworth Cengage.

[7] Longman Dictionary of Contemporary English. 2019. Pearson. Retrieved from: https://www.ldoceonline.com/

[8] Macmilllan Dictionary. 2019. Springer Nature Limited. Retrieved from: https://www.macmillandictionary.com/

[9] Merriam-Webster. 2019. Merriam-Webster Incorporated. Retrieved from: https://www.merriam-webster.com/

[10] Urban Dictionary. 2019. Urban Dictionary. Retrieved from: https://www.urbandictionary.com/ 